\title{
Corrigendum
}

CORRIGENDUM: Correction of Figure 2

\section{Polyetheretherketone Versus Titanium Cages for Posterior Lumbar Interbody Fusion: Meta-Analysis and Review of the Literature}

Elie Massaad, Nida Fatima, Ali Kiapour, Muhamed Hadzipasic, Ganesh M. Shankar, John H. Shin

Department of Neurosurgery, Massachusetts General Hospital, Harvard Medical School, Boston, MA, USA

https://doi.org/10.14245/ns.2040058.029

Neurospine 2020;17(1):125-135.

An error was found in Figure 2 on page 130 of this paper. The position of the PEEK favors and titanium favors in Figure 2 should be changed as follows:

\section{Corrected Figure 2}

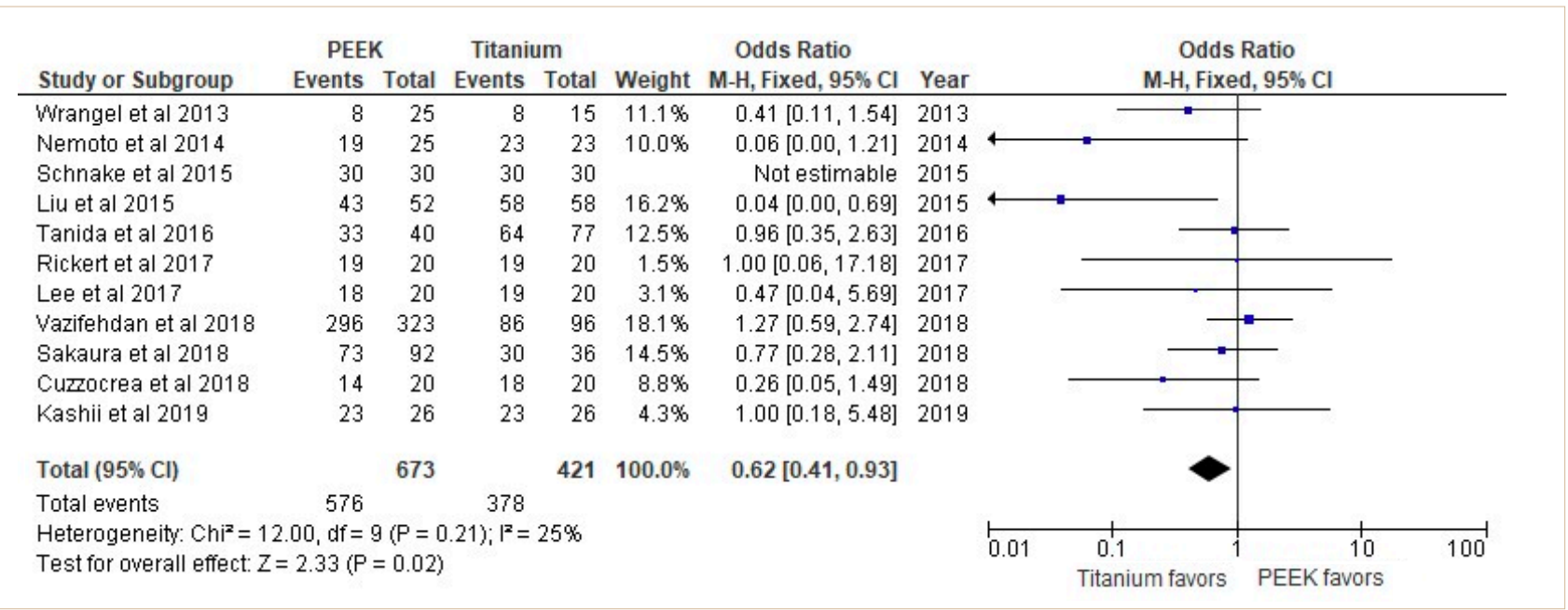

\section{(c) $(1)$}

This is an Open Access article distributed under the terms of the Creative Commons Attribution Non-Commercial License (https://creativecommons.org/licenses/by-nc/4.0/) which permits unrestricted non-commercial use, distribution, and reproduction in any medium, provided the original work is properly cited.

Copyright (C) 2020 by the Korean Spinal Neurosurgery Society 